\title{
Assessing the economic burden of injuries due to accidents: methodological problems illustrated with some examples from the literature
}

\author{
Eddy Van Doorslaer' and Lex Bouter ${ }^{2}$ \\ 'Institute for Medical Technology Assessment, Department of Health \\ Economics, ${ }^{2}$ Department of Epidemiology and Health Care Research, University \\ of Limburg, Maastricht, The Netherlands \\ Accepted 10 March 1990
}

\section{Summary}

This paper provides a survey of mothodological problems encountered in an assossment of the economlc consequences of accidents in The Notherlands. A sound opidemiologlcal basis for auch calculations appears to be lacking due to inadequate data-registration systems. We also discuses some studles of the economic costs of Injurles due to accidents for other countrles, which have ueed elther a prevalence or an incidence-based approach. It ls highlighted that they may be helpful in Indicating the relative economic burden posed on soclety but that they cannot gulde priorIty setting in health care resource allocation. Economic ovaluation studles using incidence-based scenario comparisons may be more promising in that respect.

Economic costs of iliness; Accident

\section{Introduction}

Accidents are an important cause of morbidity and mortality among the population [1]. By definition, an accident always happens to the individual unexpectedly. On the population level, however, the risks for certain subgroups can be predicted

Address for correspondence: Dr. Eddy Van Doorslaer, iMTA, Department of Health Economics, University of Limburg, P.O. Box 616, 6200 MD Maastricht, The Netherlands. 
with some precision on the basis of incidence figures from the existing registration systems. The consequences of an accident can range from very minor to an early death. Although the consequences of an accident are often manifold and can include material, physical, psychological and social aspects, the focus of this article is their expression in a monetary framework. More specifically, the attention will be directed to the assessment of economic consequences of accidents. Emphasis will be placed on the methodological problems that often severely limit the validity and reliability of the sparse existing data on this subject.

First of all, attention will be given to the several kinds of accidents and their definition. Secondly, the magnitude of the problem will be discussed in terms of incidence, severity, and medical consumption. An overview of the available descriptive data for the Netherlands is presented as an example. Thirdly, methods to calculate the costs of accidents are discussed with an emphasis on their feasibility and theoretical limitations. Some examples of empirical estimates of the costs of accidents are given. Finally, the need for economic evaluation of preventive and therapeutic strategies will be stressed.

\section{Accidents}

\section{Definitions}

Usually accidents are defined as the involuntary occurrence of sudden external forces resulting in trauma. A subdivision corresponding with the most prevalent demarcation of registration systems consists of traffic accidents, occupational accidents, and home and leisure accidents [1]. In addition to these, medical accidents, disasters, and deliberate injury possibly leading to homicide or suicide can be considered. Unfortunately, the definitions of these different categories of accidents are not mutually exclusive. Consequently, some accidents will fall in two categories (e.g., traffic accidents among professional truck drivers), while others are not covered by this classification (e.g., accidents among illegal workers) at all.

Besides this problem of definition, the current accident registration systems often do not cover the complete population at risk. In The Netherlands, for instance, occupational accidents among about $30 \%$ of those with a paid job are not registered at all [2]. Within the population covered by a registration system, a common problem is substantial underreporting, often of a selective nature (that is of certain types of accidents or of accidents among certain subgroups). These phenomena might lead to substantial impairment of the validity and the precision of data on accident frequency [1]. Whether and to what extent these technical problems indeed occur, depends on the registration system at issue, and will therefore differ from country to country and among the several categories of accidents. Miscalculation of the magnitude of the accident problem in terms of incidence, severity and medical consumption, can, of course, easily impair the assessment of the economic consequences. 


\section{Magnitude of the problem}

Basically there are two ways to assess the magnitude of the accident problem, the first being based on prevalence data, while the second departs from the incidence of accidents. The prevalence approach assesses the burden of accidents for society by estimating the average proportion of accident victims among the population at a certain moment in time (point prevalence) or over a specific period (e.g., one year; period prevalence). Prevalence data can be generated by surveys among a sample of the population in which, for instance, impairments and handicaps due to accidents are tallied [3]. A common alternative approach to the magnitude of the problem consists of measuring the medical consumption by prevalent cases of injury due to an accident. For this purpose, data from existing medical registration systems can be used. Examples are treatment by general practitioners, physiotherapists or surgeons, use of ambulances, or days spent in hospitals or in revalidation clinics.

Prevalent cases consist of already existing accident victims and new cases that originate during the period of observation. The latter are called the incident cases. The prevalence will therefore depend both on the number of new accident victims and on the duration of the consequences of the accident, while the incidence is exclusively based on the frequency of new cases. From a scientific viewpoint the incidence is a purer and thus more adequate measure, which is for instance much more sensitive to changes in accident frequency over time. Furthermore, incidence figures, some assumptions given, provide an estimate of the individual accident risk for members of the community or a certain subgroup of the population which is studied [4,5]. Incidence data for the several categories of accidents usually originate from surveys or medical registration systems. Table 1 provides an example of incidence data based on available health statistics in The Netherlands.

Mortality figures are in fact the incidence figures of fatal accidents. Table 1 presents the incidence of injury in 1984, respectively, on the level of the open population, the general practitioners, ambulances, outpatient clinics, hospitals and death certificates. Underregistration, often of a selective nature, and misclassification are important sources of error on each level. Furthermore, there may be substantial overlap between the different levels (e.g., between hospital figures and mortality) [1]. The figures of Table 1 provide some rough information on the severity of injuries due to accidents as well. More specific information on the nature

Table 1

Incidence of injury due to accidents in The Netherlands in 1984

\begin{tabular}{lllllll}
\hline & Population & & \multicolumn{3}{c}{ Medical consumption } & Mortality \\
\cline { 5 - 6 } & level & GP & Ambulance & Outpatient & Hospital & \\
\hline Traffic & 367 & n.a. & 395 & n.a. & 163 & 12 \\
Occupational & 402 & n.a. & 38 & n.a. & 24 & 0.3 \\
Home \& Leisure & n.a. & 2426 & 236 & 4596 & 496 & 15 \\
\hline
\end{tabular}

n.a., data not available.

Incidence per 100000 persons of the general population.

Source: based on available registration systems as summarized in Van Beek et al., 1988. 
of the lesions may be available in the form of a subdivision using, for instance, the categories of the International Classification of Diseases. For the assessment of the (acute) severity of the injuries some scales (e.g., abbreviated injury score and injury severity score [6]) are developed, which unfortunately are not used on a routine basis in the current Dutch registration systems. For assessment of the long term consequences of injury due to accidents, the International Classification of Impairments, Disability and Handicaps [7] is available, but this scale is still seldomly used.

\section{Example: Sports injuries}

Roughly half of the home and leisure accidents consist of sports injuries [8,9]. Recently much attention has been given to this negative side of sports participation. Table 2 summarizes the available data on the incidence of sports injuries in The Netherlands.

The comparability of the figures in this table is seriously impaired because different definitions of sports participation and sports injuries have been used. Furthermore, there are substantial differences in design, study population and time span over which the data were collected retrospectively. Most studies from Table 2 operationalize sports injuries by medical consumption. Another source of incomparability among these incidence figures are the differences in the denominator they use, that is: the number of sports participants who form the population at risk for a sports injury. The estimates for sports participation, on which the incidence figures of Table 1 are based, range from 20 to $70 \%$ of the Dutch population.

An important element in the definition of a sports participant consists of the minimal (weekly) number of hours spent on active participation. Such a cut-off point will always be arbitrary, and therefore it is more informative to express the incidence as the number of injuries per 1000 hours of sports participation. From this figure the individual risk for a sporter can be calculated while adjusting for differences in the number of hours spent sporting. In Table 3 the data from a recent telephone survey on sports injuries during the past four weeks are presented.

Table 2

Incidence a oports Injurles in The Netherlands

\begin{tabular}{lllr}
\hline $\begin{array}{l}\text { Author } \\
\text { year }\end{array}$ & $\begin{array}{l}\text { Injury } \\
\text { definition }\end{array}$ & $\begin{array}{l}\text { Number of } \\
\text { injuries }\end{array}$ & Incidence \\
\hline $\begin{array}{llll}\text { Boersma-Slutter } \\
\text { et al. 1979 }\end{array}$ & Medically treated & 573000 & 10 \\
Kranenborg, 1980 & General practitioner & 585000 & 23 \\
& Not medically treated & 591000 & 24 \\
Rogmans, 1982 & Medically treated & 506000 & 8 \\
Inklaar, 1985 & General practitioner & 240000 & 2 \\
Pors, 1987 & Outpatient clinics & 166000 & 3 \\
\hline
\end{tabular}

Based on available data as summarized in Van Galen, 1990.

Expressed per 100 sport participants per year.

bxtrapolated to the total Dutch population. 
Table 3

Incidence of sports injurles in The Notherlands in 1987 per 1000 hours of sport participation

\begin{tabular}{lll}
\hline Injury definition & Number of injuries & Incidence \\
\hline Medically treated & 1174000 & 1.4 \\
Not medically treated & 1526000 & 1.8 \\
Total & 2700000 & 3.2 \\
\hline
\end{tabular}

Data based on Van Galen, 1990.

Surprisingly, this superior methodology leads to an estimate of medically treated injuries that is $100 \%$ higher than that from former studies, while the number of not medically treated lesions turns out to be even three times the earlier estimation. Unfortunately, only limited and incomplete data on severity in terms of medical consumption, permanent disability, and absenteeism from work and sports are available from this survey $[8,9]$.

This example illustrates the fact that valid and precise estimates of the frequency (incidence or prevalence) of injury due to accidents will often not be available. Because these estimates form the basis of any calculation of the costs of accidents, the problems mentioned in this paragraph have direct consequences for the validity and reliability of these calculations as well.

\section{Costs of accidents}

\section{Cost-of-illness studies}

Since Rice's [10] first attempt to estimate the societal costs associated with the large ICD categories in the U.S.A., a number of so-called cost-of-illness (COI) studies have been undertaken for various countries. The economic burden resulting from a disease is assessed in terms of all costs - both within and outside the health care sector - resulting from the occurrence of the disease. The usefulness of this type of analysis has been hotly debated in the literature recently. Critics argue that 'COI studies only confuse, mask and mislead' [11] because, among other things, these disease cost estimates may erroneously be interpreted as the benefits to be gained from better treatment or even prevention of the disease. Clearly, because COI studies lump together the total costs of prevention, diagnosis, treatment, rehabilitation and the production losses due to morbidity and mortality, the distinction between costs made to avoid detrimental effects of the disease and potential benefits to be gained from interventions becomes fuzzy. Precisely for this reason Feldstein [12] stated more than 25 years ago that COI studies represented a method for 'calculating the benefits of unattainable goals'.

The state-of-the-art seems to be that the critics have correctly pointed out that COI studies have little, if anything, to offer for decision making about allocation of scarce resources, because they do not link costs and benefits in a very systematic way. They merely indicate the relative economic burden of different disease categories, but give no guidance as to how resources could be allocated more 
efficiently. For the latter purpose, economic appraisal methods such as cost-benefit or cost-effectiveness analysis are better suited [13].

Despite its limitations, we will give a summary of the evidence to date on the costs associated with injuries due to accidents. No comprehensive studies on costof-illness have been done for The Netherlands. Therefore, in order to be able to establish the relative importance of accidents in terms of the burden placed on society, we will have to rely on results from other countries.

\section{Methodological problems}

\section{Prevalence versus incidence approach}

First of all, a distinction has to be made between different approaches to estimating costs of illness. The studies referred to in the previous section all adopted the prevalence-based approach by looking only at the costs attributable to the prevalent cases in a fixed period of time. They tried to identify all health care costs and productivity losses owing to sickness (or injury) that accrued during that year to persons suffering from the condition under consideration. All costs considered therefore refer to the same year, with one exception: the lost future earnings of persons dying of the condition in that particular year are also counted.

The incidence-based approach, on the other hand, focuses only on the costs associated with those disease or injury cases incident in the year at issue. For all those incident cases a present value equivalent for both health care expenditures and lost productivity is calculated, regardless of the time of occurrence, be it during that year or during some year in the future.

Clearly, for the acute consequences of injury due to accidents, the estimates from both approaches should be very close to one another, but for the more chronic consequences with secular trends in their severity they may well lead to very different results. The choice for one approach or the other should be dependent on the objectives of the study. If the only aim is to examine what the current cconomic consequences are of (mainly) developments in the past, then the prevalence approach may provide useful information for the policy maker concerned with current medical costs and absenteeism. However, if the interest lies in the anticipated future consequences of (again mainly) current developments, then the incidence approach is more suited for the policy maker who has to choose now between alternative strategies for the future.

In the context of injuries due to accidents, a prevalence approach might, for instance, produce valuable information for decisions to be taken about rehabilitation programs for prevalent accident victims, while the incidence approach is more suited when alternative prevention strategies are being considered.

Direct versus indirect economic costs

Because the productive resources available to treat diseases are not unlimited, every society faces the basic problem of how to allocate these finite resources optimally. Inevitably, employing resources in one particular use implies that they cannot be used in some alternative way. The latter statement automatically refers to the definition of economic costs: they represent the benefits which could have been 
obtained from its best alternative use. In line with this notion of lost opportunities, they are also called opportunity costs.

Within the context of the problem at hand, it becomes necessary to identify the consequences of accidents that result in lost production and forgone alternatives.

The costs associated with a disease or injury can be classified into direct and indirect costs. Direct costs represent the value of resources used to prevent, detect, treat, and rehabilitate the health impairment or its effects. Within the health care sector, they include expenditures for emergency assistance, hospitalization, physicians' and surgeons' services, paramedical services, outpatient clinical care, nursing home care, drugs, medical appliances, etc. In addition, there are often non-health sector costs borne by the patient and others, e.g.home modifications, institutional help, travel expenses, etc. Indirect costs bear a more implicit relationship to the health impairment. Its primary component is the lost or forgone productivity of patients suffering from premature death or disability. How should this loss to society be valued? Basically, two approaches have been used in the literature. The human-capital approach is based on the use of a person's expected lifetime earnings, calculated back to the year of incidence, as a surrogate measure of the future productive worth if the disease or injury had not occurred. This is done by a procedure named discounting, which refers to the conversion of future costs or benefits into a present value. For the technical details of the discounting procedure [13]. Because this method immediately leads to the question of how to value the lives of the non-active and the elderly population, some researchers have favoured the alternative willingness-to-pay approach. In that approach, the total societal value of life is proxied by the amount that one would be willing to pay to extend life or to reduce the risk of death or health impairment. It has been used particularly with respect to the valuations of reductions in the risk of road traffic accidents, not so much for cost-benefit analyses of health care projects but for road and transport safety investment projects $[14,15]$. Obviously, both approaches suffer from serious drawbacks [16] for a more detailed discussion. In addition to the general recognition that the human capital approach considers only one aspect of human value, i.e., work, measurement problems remain with respect to the estimation of expected future earnings, the valuation of non-market labour, the choice of the appropriate discount rate etc. However, the difficulties and biases involved in eliciting preferences from individuals when life-threatening situations are at stake, make the willingness-to-pay approach even less attractive for researchers and policy-makers confronted with actual decisions. It is therefore not surprising that most cost-ofillness studies performed to date have only used discounted future eamings as an approximation of the (productive) value of a human life.

\section{Results: some empirical estimates of the costs of accidents}

Keeping in mind the limitations of both approaches to cost-of-illness estimation, we will give a brief overview of the results to date in the international literature and, where available, for The Netherlands. 


\section{Incidence approach}

Because of the complexity involved in modelling the disease or injury process from onset until cure or death, relatively few incidence based studies exist. Policy Analysis Inc. [17] examined the costs of breast cancer, diabetes mellitus, rheumatoid arhtritis, stroke and acute lymphocytic leukemia, while Hartunian, Smart and Thompson $[16,18]$ estimated the costs of cancer, coronary heart disease, stroke and motor vehicle injuries for the United States in 1975. Table 4 presents the estimated direct and indirect costs of motor vehicle injuries in the U.S.A. as a function of the Maximum Abbreviated Injury Severity Score (MAISS). It shows that the direct costs increase with injury severity level with one exception: fatal injuries account for the lowest direct but the highest indirect costs. From Fig. 1 it can be seen that for all four major health impairments considered, the indirect costs of forgone earnings are much higher than the direct costs associated with treatment. Total costs of motor vehicle injuries, i.e., only a subset of all traffic accidents, are slightly higher than coronary heart disease costs and this is due to its much higher direct costs.

No comparable study is available for The Netherlands, although one of the projects coordinated by the Steering Committee on Future Health Scenarios in the Netherlands provides the opportunity to perform an analysis which approximates such an incidence approach. For the scenarioproject 'Accidents in the year 2000' for instance, a computer simulation model was developed to predict the effects of different scenarios of exposure and risks for injuries and fatalities due to traffic, occupational, and home and leisure accidents. The results on accident mortality are described in Van Beek et al. [1]. In principle, the reference scenario, expressing the most likely future developments, could have been used for an incidence based estimate of the costs due to accidents in The Netherlands in 1985. However, no attempt was made to calculate the cost consequences.

Table 4

Estimated direct and indirect costs associated with the incidence of motor vehicle injuries, U.S.A. 1975; dlatribution by injury-eoverity lovel

\begin{tabular}{lccc}
\hline Injury-severity level & \multicolumn{2}{c}{ Costs (million of dollars) } & \\
\cline { 2 - 4 } & Direct & Indirect & Total \\
\hline Fatal & 176 & 7062 & 7228 \\
Minor (MAIS1) & 632 & 111 & 743 \\
Moderate & 797 & 180 & 977 \\
Serious & 970 & 314 & 1284 \\
Severe & 665 & 206 & 871 \\
Critical (MAIS5) & 1533 & 1798 & 3331 \\
All & 4773 & 9662 & 14435 \\
\hline
\end{tabular}

MAIS, Maximum Abbreviated Injury Scale.

Source: Hartunian et al. 1981. 


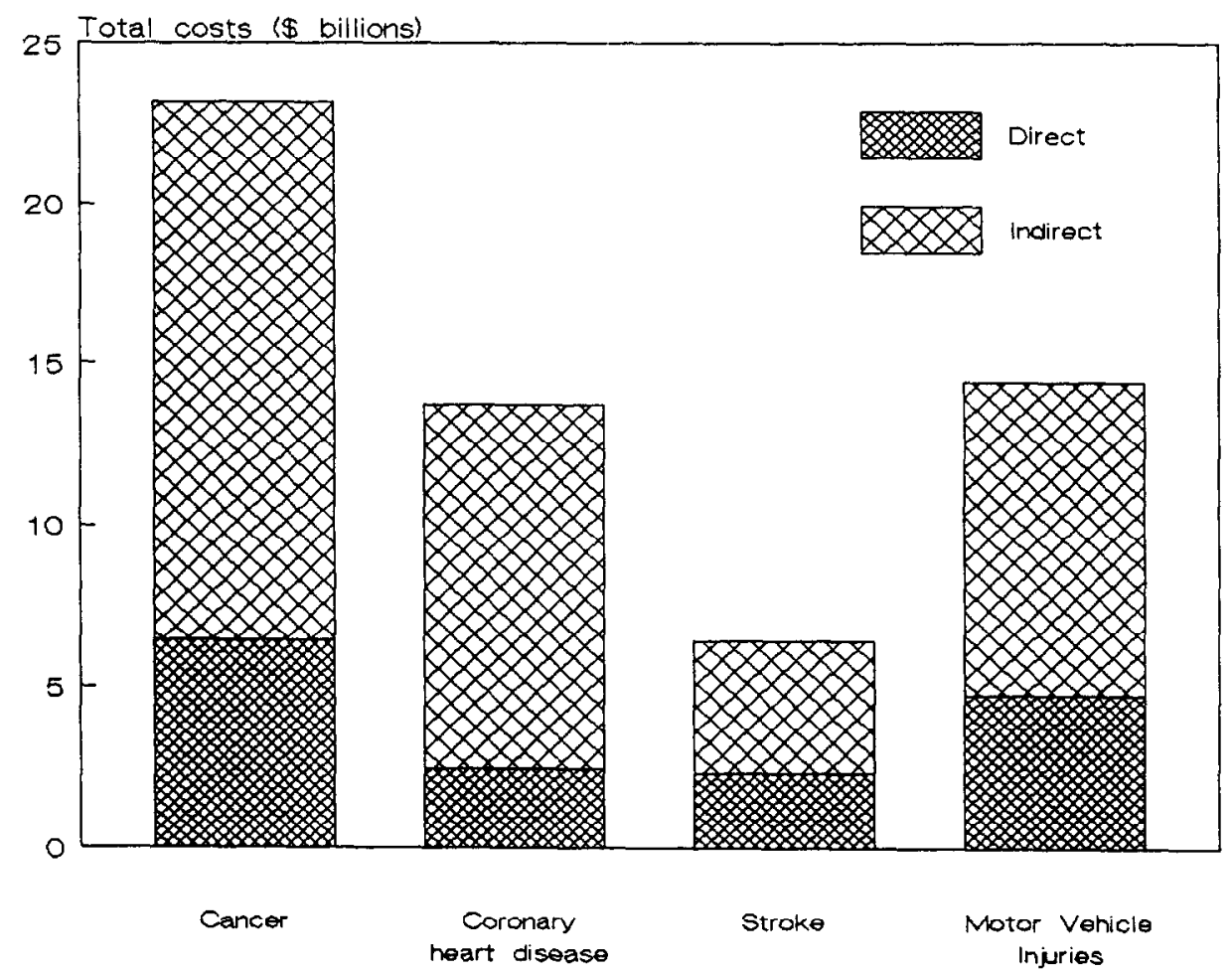

Fig. 1 Total economic costs asecclated with the incidence of cancer, coronary heart disease, stroke and motor vohicle Injurles, U.S.A., 1975. All costs are in 1975 dollars, dlecounted at 6\%. (Source: Hertunian of al., 1981.)

\section{Prevalence approach}

Prevalence based estimates of costs of illnesses are much more abundant in the literature. A recent survey of the results of comprehensive (i.e., encompassing all major ICD categories) studies was given by Hagen [19]. This type of COI studies usually distinguishes between three cost components: direct costs of illness or injury, indirect costs of illness or disability, and indirect costs of mortality. As we mentioned before, the latter component also includes costs due to expected loss of future life years, while the first two components only refer to the base year. It appears that accidents account for, on average, about $7 \%$ of all health care (i.e., direct) costs with surprisingly little variation between the countries considered.

In order to obtain a better insight as to how this relative position of injury costs versus other disease categories is obtained, it is instructive to focus on the two most recent studies. German figures for 1980 are presented in Table 5 and taken from Henke and Behrens [20]. They show that whereas accidents only have rank 4 in the listing of disease categories by health care direct costs incurred (with 7.5\%), they come out as the leading cause of indirect costs of mortality (with $28 \%$ of the total). This is, of course, not because it is the most important cause of mortality 
Table 5

Direct and Indirect costs by diagnosis for 'cost top five' in the F.R.G. and the U.S.A.a

F.R.G.

\begin{tabular}{lcclc}
\hline & Direct costs & \multicolumn{2}{c}{ Indirect costs } & Total \\
\cline { 3 - 4 } & & Mortality $^{\mathrm{b}}$ & Morbitity & costs \\
\hline Digestive system & 25.8 & 8.8 & 10.3 & 18.8 \\
Circulatory system & 14.2 & 22.4 & 10.5 & 14.8 \\
Injuries & 7.5 & 28.4 & 15.3 & 13.2 \\
Bones and organs of & & 0.2 & 19.9 & 9.6 \\
movement & 8.1 & 3.0 & 16.3 & 8.4 \\
Respiratory system & 6.6 & 27.831 & 66.862 & 154.324 \\
Total (in million DM) & 87.462 & & & \\
\hline
\end{tabular}

Source: Henke and Behrens (1986).

U.S.A. (1980)

\begin{tabular}{lcccc}
\hline & Direct costs & \multicolumn{2}{c}{ Indirect costs } & Total \\
\cline { 3 - 4 } & & Mortality & Morbitity & costs \\
\hline Circulatory system & 15.4 & 23.3 & 16.9 & 18.7 \\
Injury and poisoning & 8.8 & 32.4 & 10.7 & 18.2 \\
Neoplams & 6.2 & 18.0 & 8.5 & 11.1 \\
Digestive system & 14.7 & 4.6 & 5.1 & 9.3 \\
Respiratory system & 7.9 & 3.6 & 15.0 & 7.3 \\
Total (in million \$) & 211.143 & 175.912 & 67.827 & 454.882 \\
\hline
\end{tabular}

Source: Rice et al. (1985).

- All cost figures are expressed as a percentage of the total for all disease categories.

b Indirect costs of mortality have been discounted at $4 \%$.

(it comes third, after diseases of the circulatory system and neoplasms), but rather because it causes deaths at, on average, younger ages and therefore induces many more life years lost to productivity.

On the whole, summing all direct and indirect economic costs of illness, disability and death in the Federal Republic of Germany in 1980, accidents are estimated to account for DM 20.4 billion or $13.2 \%$ of the total costs of illnesses. With this figure it ranks third, after diseases of the digestive system (18.8\%) and diseases of the circulatory system (14.8\%).

Comparable figures are presented for the United States in 1980 by Rice et al. [10]. Injuries take an even more prominent position in the American top five of cost causing diagnoses. This is mainly due to a much higher estimate of the indirect costs of mortality due to accidents. Rice et al. [10] have also presented a subdivision of deaths and person years lost by age. Despite the fact that diseases of the circulatory system cause 6 times more deaths than injuries, the estimated productivity loss is substantially lower. This is because only about $20 \%$ of these deaths were at ages below 65, whereas the majority of deaths due to injuries (i.e., 80\%) occur at ages under 65 years.

No such comprehensive COI study exists for The Netherlands but attempts have been made to calculate detailed estimates of economic costs associated with specific 
types of accidents. Den Toom and Schuurman [21], for instance, have developed a sort of accounting model to calculate the annual direct costs and indirect costs of morbidity for home and leisure accidents in The Netherlands. This model does give an indication of the magnitude of annual expenditures on health care and disability payments, but we do not support the claim that it may also be useful for priority setting in prevention. For that purpose, information is needed on the relative cost-effectiveness of altemative types of intervention which can only be obtained from rigorous evaluation studies.

Examples of evaluation studies about injuries due to accidents are even more scarce than COI studies. O'Connor et al. [22] recently reported on a cost-benefit analysis of a bicycle helmet program. The health and economic implications of increasing the wearing of bicycle helmets among males aged 5-19 were calculated on the basis of assumptions based on the literature. It was found that such a program would be cost-saving and that this result was relatively insensitive to variations in helmet efficacy, compliance, accident rate and program costs. They conclude that 'Despite sparse published epidemiological data, this analysis strongly supports the widespread encouragement of bicycle helmet use and demonstrates the use of costbenefit analysis in the planning of injury prevention programs' (p. 329).

Similarly, on a more aggregate level, scenario-simulation models such as the one developed by Van Beek et al. [23] could be used for economic evaluation by comparing costs and effects in a reference scenario with the simulated costs and effects of altemative scenarios for care and prevention. If feasible, the macro-level cost-effectiveness ratios derived from such exercises would clearly be much more valuable for policy-making purposes than the descriptive information obtained from COI studies.

\section{Conclusion}

Valid and precise information on the magnitude of the injury problem in terms of frequency (incidence or prevalence), severity and medical consumption, forms a necessary (but not a sufficient) condition for the calculation of the economic consequences. It appears that the availability of these data is rather limited, while the reliability is often questionable and large biases can easily arise in the registration procedures. Consequently, available estimates of costs of injuries due to accidents should be looked upon with caution.

In this paper we also hope to have made clear what estimates of the economic costs of injuries due to accidents can and what they cannot be used for. By indicating the relative economic burden posed on society, such estimates may be helpful in setting priorities for research policy. However, because they do not indicate what part of the burden is potentially avoidable, they cannot guide priority setting in resource allocation.

In trying to accomplish the latter aim, the techniques of economic evaluation (such as cost-benefit, cost-effectiveness and cost-utility analysis [13]) are much more helpful. Systematic comparisons of alternative courses of action in terms of 
both costs and (ultimately health) effects may indicate instances where efficiency improvement is actually attainable in practice.

A search through the literature for cost-effectiveness studies dealing with the injury problem indeed confirms that there is a gap in the current knowledge. A shift from the current emphasis on cost estimation towards more evaluative studies therefore seems highly warranted.

\section{References}

1 Van Beek, E.F., Mackenbach, J.P., Habbema, J.D.F. and Van der Maas, P.J., Achtergrondstudie scenario-onderzoek 'ongevallen en traumatologie', in: Stuurgroep Toekomstscenario's Gezondheidszorg. Ongevallen in het jaar 2000, Deel 2: Achtergrondstudies en wetenschappelijke verantwoording. Utrecht, Bohn, Scheltema \& Holkema, 1988, pp. 1-130.

2 Smit, J., De bruikbaarheid van de statistiek der bedrijfsongevallen voor epidemiologisch onderzoek. Tijdschrift voor Sociale Gezondheidszorg, 63 (1985) 910-914.

3 CBS, Gehandicapten welgeteld: lichamelijk gehandicapten 1971/1972, 's-Gravenhage, CBS, 1974.

4 Rothman, K.J., Modern epidemiology, Boston, Little, Brown and Company, 1986.

5 Kelsey, J.L., Thompson, W.D. and Evans, A.S., Methods in observational epidemiology, New York, Oxford University Press, 1986.

6 Baker, S.P. et al., The injury severity score: a method for describing patients with multiple injuries and evaluating emergency care, Joumal of Traumalogy, 14 (1974) 187-196.

7 Wood, P.H.N., Appreciating the consequences of disease: the ICIDH, WHO Chron, 34 (1980) 376-380.

8 Van Galen, W. and Diederiks, J., Sportblessures breed uitgemeten, Haarlem, De Vrieseborch, 1990.

9 Van Montfoort, G.L.M., Van Galen, W.Ch.C. and Harris, S., Ongevallen in Nederland: een onderzoek naar privé-, verkeers-, sport- en bedrijfsongevallen in de periode augustus 1986-angustus 1987. Amsterdam, SCV, 1988.

10 Rice, P.D., Hodgson, T.A. and Kopstein, A.N., The economic costs of illness: a replication and update, Health Care Financing Review, 7 (1985) 61-80.

11 Shiell, A., Gerard, K and Donaldson, C., Cost of illness studies: an aid to decision making?, Health Policy, 8 (1987) 317-323.

12 Feldstein, M.S., Review of B.A. Weisbrod's 'The economics of public health: measuring the economic impact of diseases, Economic Journal, 73 (1963) 129-130.

13 Drummond, M.F., G.L. Stoddart and Torrance, G.W., Methods for the economic evaluation of health care programmes, Oxford University Press, Oxford, 1987.

14 Jones-Lee, M.W., The value of life and safety: a survey of recent developments, The Geneva Papers on Risk and Insurance, 10 (1985) 141-173.

15 Persson, V., The value of risk reduction: results of a Swedish sample survey, paper presented at the Joint Meeting of the European Health Economics Societies, September 1989.

16 Hartunian, N.S., Smart, C.N. and Thompson, M.S., The incidence and economic costs of major health impairments, Lexington Books, 1981.

17 Policy Analysis, Inc., Evaluation of cost of illness ascertainment methodology, Part II. Applications of methodology to ascertain lifetime economic costs of illness in an incidence cohort, Final Report, DHHS Contract No. 233-79-2048, December 1981.

18 Hartunian, N.S., Smart, C.N., Thompson, M.S., The incidence and economic costs of cancer, motor vehicle injuries, coronary heart disease and stroke: a comparative analysis, American Journal of Public Health, 70 (1980) 1249.

19 Hagen, H., Economie en gezondheid, in: R.M. Lapre en F.F.H. Rutten (red.), Economie van de gezondheidszorg, De Tijdstroom, Lochem, 1988.

20 Henke, K.D. and Behrens, C.S., The economic costs of illness in the Federal Republic of Germany in the year 1980, Health Policy, 6 (1986) 119-143.

21 Den Toom and Schuurman, Een model voor de berekening van kosten van ongevallen in de privéfeer, Stichting Consument en Veiligheid, 1988, 207 p. 
22 O'Connor, M.A.S., Beck, J.R., Metz, S.E., O'Connor, G.T., Boyle Jr., W.E., Keller, M. and Zubkoff, M., Estimated cost-benefit analysis of a bicycle helmet program, abstract, Medical Decision Making, 9, 4 (1989) 329.

23 Beek, E.F. van, Mackenbach, J.P., Van Oortmarssen, G.J., Barendregt, J.J.M., Habbema J.D.F. and Van der Maas, P.J., Scenarios for the future development of accident mortality in the Netherlands, Health Policy, 11 (1989) 1-17. 